Jaqueline Melo SOARES ${ }^{1}$ Marcelo Emílio BELETTI ${ }^{1}$

\section{Correspondência para:}

JAQUELINEMELOSOARES

Centro de Ciências Biomédicas.

Universidade Federal de Uberlândia

Av: Pará, 1720

38405-320 - Umuarama-MG

soaresjaqueline@uol.com.br

mebeletti@centershop.com.br

Recebido para publicação: 23/03/2004 Aprovado para publicação: 13/02/2006

\title{
Avaliação da morfologia e da compactação cromatínica em espermatozóides de galo (Gallus gallus, Linnaeus, 1758) através de microscopia eletrônica de transmissão
}

1 - Centro de Ciências Biomédicas da Universidade Federal de Uberlândia, Umuarama - MG

\author{
Resumo \\ O espermograma é um dos principais métodos de avaliação da \\ fertilidade em mamíferos, contudo, algumas alterações do sêmen \\ como a compactação da cromatina dos espermatozóides, não são \\ Palavras-chave: \\ Galo. \\ Espermatozóide. \\ Compactação de cromatina. \\ Fertilidade \\ Ultra-estrutura.
} identificadas nessa rotina, podendo interferir significativamente na fertilidade de reprodutores. $\mathrm{Na}$ avicultura, geralmente a avaliação de reprodutores é feita por amostragem e os parâmetros avaliados são em menor número que em mamíferos, sendo que a compactação da cromatina dos espermatozóides de galo nunca foi explorada. Este trabalho teve como objetivo verificar através da microscopia eletrônica de transmissão, se existe diferentes intensidades de compactação de cromatina em espermatozóides de galo. Para isto, foram coletadas 20 amostras de sêmen de galo, que foram fixadas por 48 horas em glutaraldeído 4\% tamponado em cacodilato de sódio $0,1 \mathrm{M}$ a pH 7,2, após centrifugado e lavado em tampão cacodilato o sêmen foi pósfixados em tetróxido de ósmio a 1\% mais ferrocianeto de potássio a $1,25 \%$. O sedimento foi incluído, cortado e posteriormente contrastado. Os cortes foram examinados e documentados em microscópio eletrônico Zeiss EM-109. Geralmente, os espermatozóides de galo possuem acrossoma com material homogêneo ou levemente granular e de densidade moderada, o núcleo com cromatina densa e levemente granular, varia as tonalidades de cinza, ou seja, os graus de compactação. Observou-se também o "perforatorium", estrutura que une o núcleo ao acrossoma. A inserção da cauda é por meio de dois centríolos, sendo um transversal e o outro longitudinal ao eixo. A peça intermediária possui axonema típico envolto por mitocôndrias aparentemente dispostas longitudinalmente. A transição entre as peças intermediária e principal da cauda é marcada pela ausência das mitocôndrias. A peça principal é formada pelo axonema envolto por uma camada de citoplasma granular. $\mathrm{Na}$ avaliação das patologias morfológicas observaram-se cabeças arredondadas, dobradas, envoltas por conteúdo da peça intermediária, em anzol e todas apresentando diferentes graus de compactação.

\section{Introdução}

A espermatogênese é o processo pelo qual as espermatogônias originam os espermatozóides. Ocorre no interior dos túbulos seminíferos, responsáveis pela produção de gametas, e no ducto epididimário, que colabora no processo de maturação dos espermatozóides. A espermatogênese corresponde a eventos seriados que envolvem modificações nucleares e citoplasmáticas, resultando em 
células haplóides altamente móveis e adaptadas para sobreviver por longos períodos fora do corpo ${ }^{1,2,3,4,5}$. Segundo Gilbert o tempo de maturação dos espermatozóides no testículo das aves varia para cada espécie. Normalmente as espermatogônias se multiplicam por volta da quinta semana após o nascimento da ave, e os espermatócitos primários aparecerem próximo da sexta semana de vida. Cerca da décima semana estas células se multiplicam intensamente, e observa-se a presença de espermatócitos secundários aumentando o volume dos túbulos. Então, aparecem as primeiras espermátides, num fluxo contínuo até a vigésima semana. Após esse período, os testículos estão aptos a produzir espermatozóides em volume, para garantir a fertilização na cópula.

$\mathrm{Na}$ espermiogênese dos mamíferos, aves e muitos peixes, as histonas são total ou parcialmente substituídas por nucleoproteínas denominadas protaminas, proteínas de caráter mais básico que as histonas e com abundância de arginina e cisteína oxidada ${ }^{6}$. Tais proteínas dão origem a uma cromatina extremamente condensada e inerte, pois os resíduos amina dessas proteínas interagem com a fita de DNA através de seus grupos fosfatos, neutralizando o esqueleto fosfodiéster, sendo esta interação denominada complexo DNAproteína ou simplesmente cromatina. No caso das aves, a protamina presente no núcleo da célula espermática é conhecida como galline $^{12,14}$. A cromatina apresenta maior ou menor grau de compactação, sendo esse fator de grande relevância, quando avaliamos células espermáticas e a fertilidade nos machos.

O espermograma é um dos principais métodos de avaliação da fertilidade em machos de mamíferos, contudo, algumas alterações do sêmen como a compactação da cromatina dos espermatozóides, não são identificadas nessa rotina, podendo interferir significativamente na fertilidade de reprodutores. $\mathrm{Na}$ avicultura, geralmente a avaliação de reprodutores é feita por amostragem e os parâmetros avaliados são em menor número que em mamíferos, sendo que a compactação da cromatina dos espermatozóides de galo nunca foi explorada. Este trabalho teve como objetivo verificar através da microscopia eletrônica de transmissão, se existe diferentes intensidades de compactação de cromatina em espermatozóides de galo, principalmente em espermatozóides morfologicamente anômalos.

\section{Materiais e Métodos}

Para coleta de sêmen foi utilizada a técnica descrita por Wilson ${ }^{15}$, o qual recomenda suaves massagens abdominais na ave com uma das mãos do coletor, diminuindo a influência de outros líquidos que compõem o sêmen e mantendo a integridade do tecido epitelial da região cloacal, sendo que a mão oposta, massageia a região inferior da ave e penas da cauda.

Foram coletadas 20 amostras de sêmen de galo (Gallus gallus, Linnaeus, 1758) através de massagem cloacal segundo Wilson ${ }^{15}$.

As amostras de sêmen de galo foram processadas para microscopia eletrônica de transmissão. O sêmen foi coletado em tubos com glutaraldeído 4\% tamponado em cacodilato de sódio $0,1 \mathrm{M}$ a pH 7,2. Após a fixação por 48 horas, o sêmen foi centrifugado $\left(\mathrm{g}=1,06 \times 10^{3}\right)$, em seguida lavado em tampão cacodilato $(0,1 \mathrm{M}, \mathrm{pH} 7,2)$ duas vezes por 10 minutos e então, pós-fixados por quatro horas em glutaraldeído a 3\% e uma hora em tetróxido de ósmio a 1\% mais ferrocianeto de potássio a 1,25\%. Finalmente, o sedimento foi incluído em resina epon e posteriormente foi cortado em ultramicrótomo para obtenção de cortes ultrafinos. Os cortes foram contrastados com acetato de uranila ${ }^{16} \mathrm{e}$ citrato de chumbo ${ }^{17}$. Estes cortes foram examinados em microscópio eletrônico Zeiss EM-109, sendo realizada a documentação fotográfica.

\section{Resultados}

A avaliação dos espermatozóides de galo em microscopia eletrônica de 
transmissão foi feita de maneira descritiva e não quantitativa. De maneira geral, os espermatozóides possuem acrossoma com material homogêneo ou levemente granular e de densidade moderada (Figura 1A). Foi possível observar o "perforatorium" (Figura $1 \mathrm{~A})$, estrutura que une o núcleo ao acrossoma, encaixando-se em uma concavidade na porção apical do núcleo. No
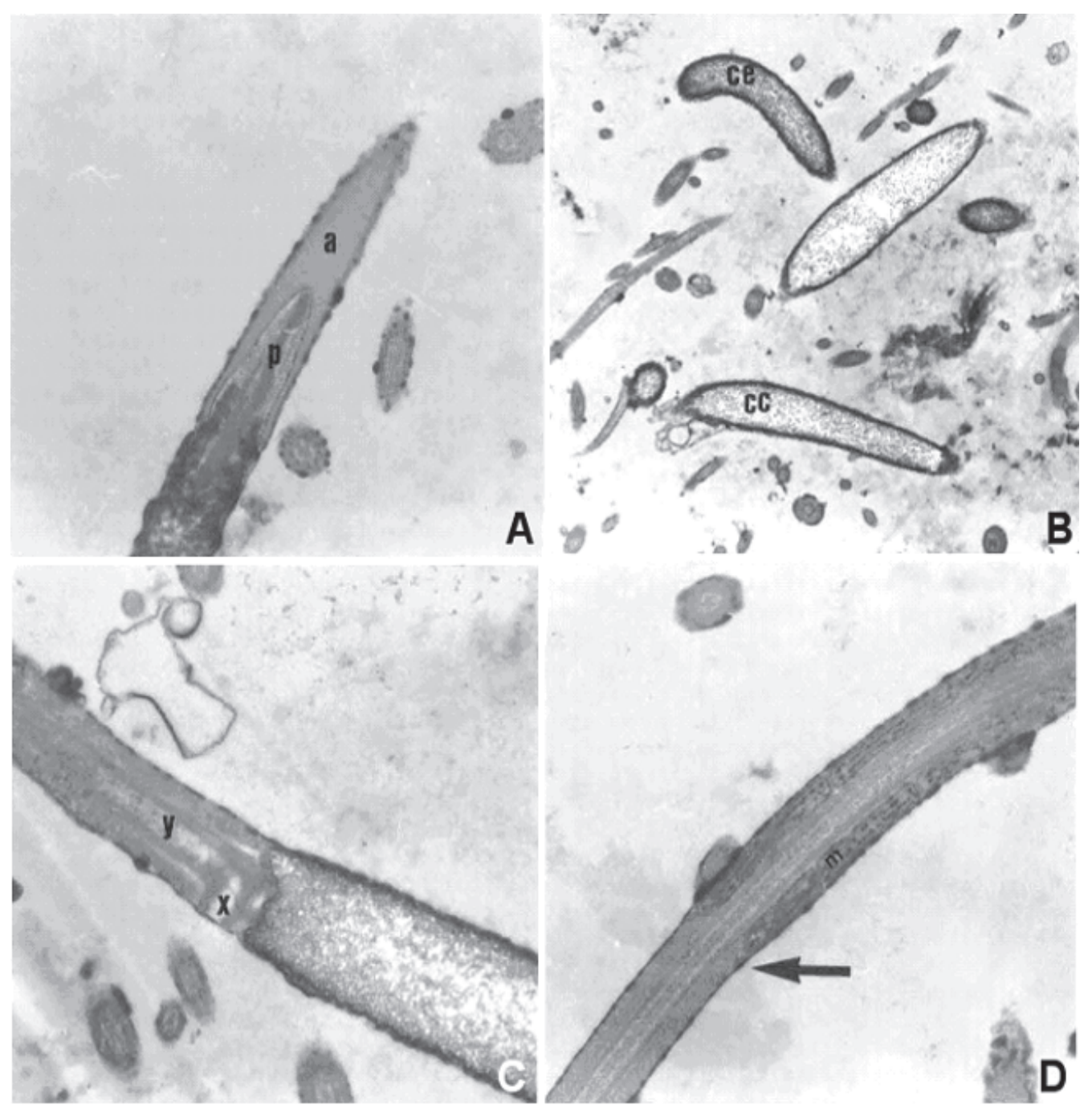

Figura 1 - A: Espermatozóide de galo onde se observa acrossoma (a) com material homogêneo e de densidade moderada e com a presença do "perforatorium" (p). (Aumento de 35.700X)

B: Espermatozóides de galo apresentando cromatina clara (cc) e cromatina escura (ce), ou seja, com várias intensidades de compactação. (Aumento de 10.800X)

C: Inserção da cauda de espermatozóide de galo, mostrando a presença de dois centríolos, sendo o proximal em posição transversal (x) e o distal em posição longitudinal (y). (Aumentode 35.700X)

D: Transição entrea peça intermediária e peça principal da cauda(seta) de espermatozóide de galo, marcada pela presença das mitocôndrias (m), não havendo uma brusca diminuição de diâmetro na transição. (Aumento de 10.800X) 

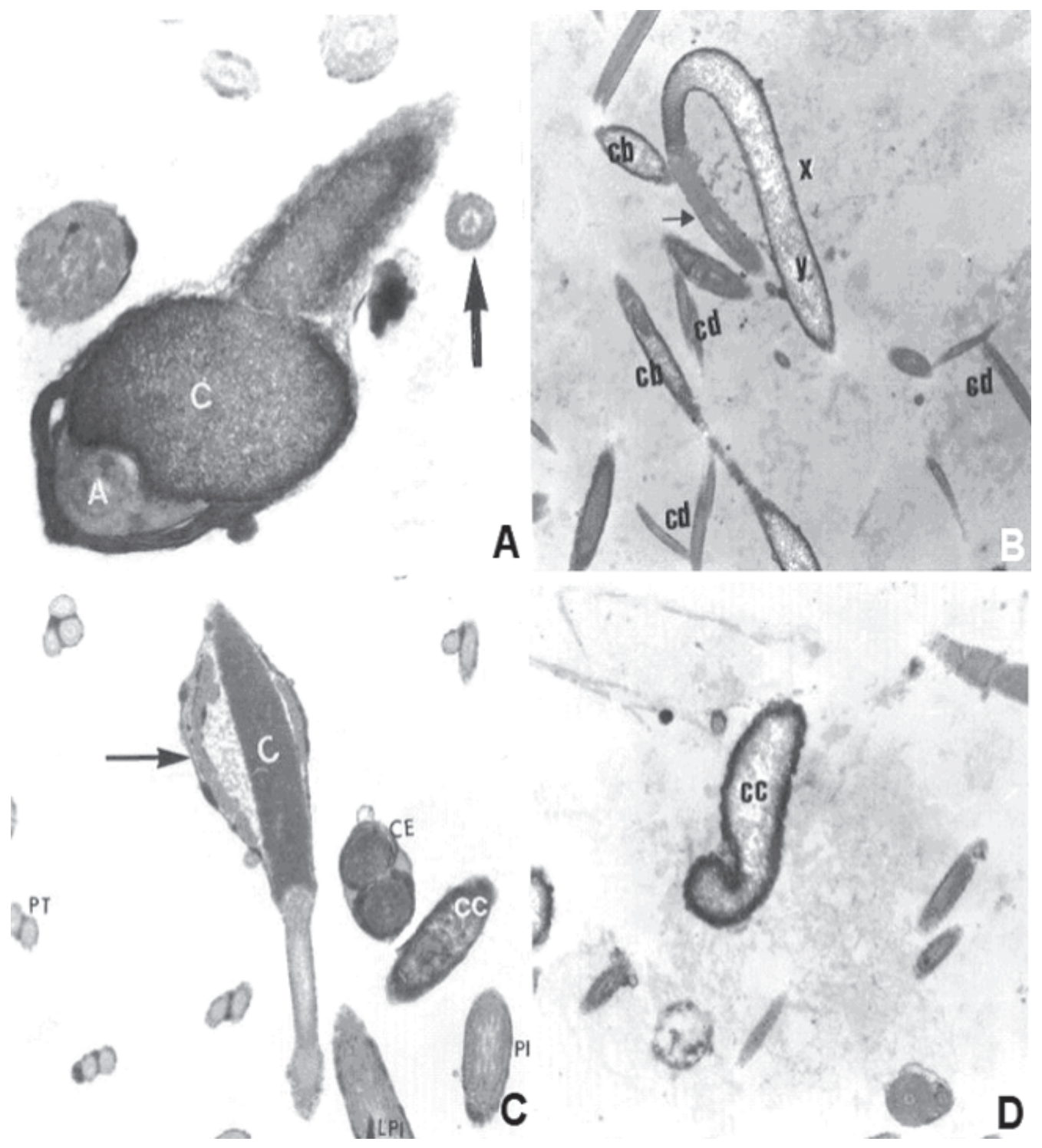

Figura 2 - A: Cabeça de espermatozóide de galo do tipo arredondada (patologia morfológica), com cromatina escura (C), acrossoma irregular (A) e cortes transversais de caudas em diferentes alturas (setas). (Aumento de 35.700X)

B: Cabeça de espermatozóide de galo dobrada (x) (patologia morfológica) e cromatina geralmente clara (y), acompanhando também parte da cauda (seta) e outros cortes longitudinais de cabeças (cb) em diferentes graus de compactação e caudas (cd) de outros espermatozóides. (Aumento de 10.800X)

C: Cabeça de espermatozóide de galo com cromatina escura (C) envolta por conteúdo da peça intermediária (seta). Presença de caudas em vários estágios de cortes transversais tanto da peça intermediária (PI), quanto de partes terminais mais afiladas (PT), corte transversal de duas cabeças unidas por uma mesma membrana (patologia morfológica) e com cromatina escura (CE), corte longitudinal de peça intermediária da cauda (LPI) e corte tangente de uma cabeça mais clara (cc). (Aumento de 19.400X)

D: Cabeça de espermatozóide de galo do tipo anzol (patologia morfológica) com cromatina clara (cc). (Aumento de 19.400X)

transversal e o distal em posição longitudinal (Figura 1C). A peça intermediária é composta de um axonema típico (com nove pares de microtúbulos periféricos e um par central) envolto por mitocôndrias aparentemente dispostas longitudinalmente (Figuras 1D). A transição entre a peça intermediária e peça principal da cauda é marcada pela ausência das mitocôndrias, não havendo uma brusca diminuição de 

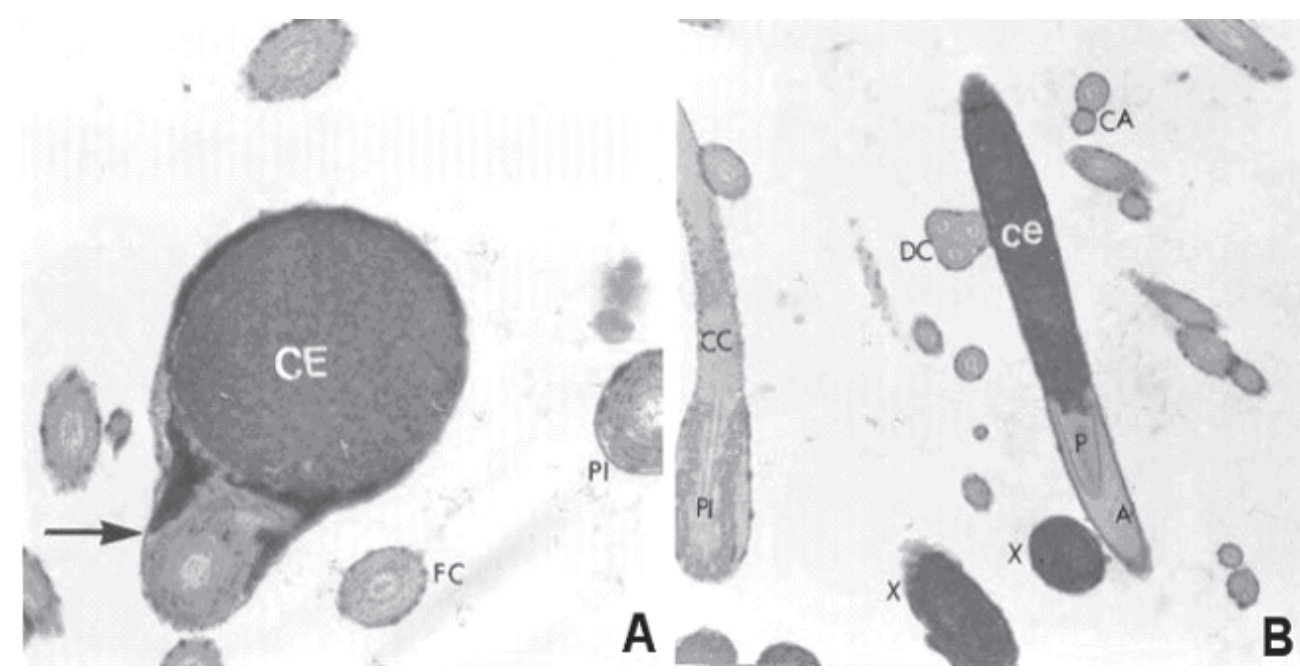

Figura 3 - A: Cabeça de espermatozóide de galo em corte transversal com cromatina escura (CE) e cauda dobrada sobre a mesma (patologia morfológica) (seta), sendo possível à visualização de caudas em vários estágios desde a peça intermediária (PI), até o final da cauda em regiões mais afiladas (FC), também em cortes transversais. (Aumento de 35.700X)

B: Corte longitudinal de duas células espermáticas de galo, sendo possível visualizar em uma delas a cromatina escura (ce), o "perforatorium” (P) e o acrossoma (A), em outra célula temos a peça intermediária em corte longitudinal (PI) e a continuação da cauda (CC). Em corte transversal, observamos cabeças com cromatina escura $(\mathrm{X})$, caudas em regiões mais afiladas (CA) e um defeito morfológico de cauda (axonema triplo) em corte transversal (DC). (Aumento de 19.400X)

diâmetro na transição (Figura 1D). $\mathrm{Na}$ avaliação das patologias morfológicas em microscopia eletrônica observaram-se cabeças arredondadas, com cromatina geralmente escura (Figura 2A), cabeça dobrada e cromatina geralmente clara (Figura 2B), cabeça com cromatina escura envolta por conteúdo da peça intermediária (Figura 2C), cabeça em anzol com cromatina clara (Figura 2D). Patologias de cauda, também foram observadas, tais como cauda dobrada sobre a cabeça (Figura $3 \mathrm{~A})$ e caudas compostas por três axonemas (Figura 3B). A peça principal é formada pelo axonema envolto por uma camada de citoplasma granular, que diminui gradualmente, desaparecendo quase que totalmente no final da cauda, onde é composta praticamente pelo axonema e membrana citoplasmática (Figura 3B).

\section{Discussão}

O conhecimento anatômico dos órgãos reprodutivos da ave, foi necessário durante a coleta sendo a cloaca provável local de contaminação de fezes, excretas e microrganismos patogênicos, causando danos ao espermatozóide. Bakst e Bahr ${ }^{18}$ descreveram a importância da higienização das mãos do técnico e a maneira de manipular o macho, fatores que influenciam na qualidade do ejaculado.

A ultra-estrutura do espermatozóide de galo observada neste trabalho foi muito semelhante ao descrito pela literatura consultada ${ }^{19,20,21,22}$. Contudo, as mitocôndrias encontradas na peça intermediária aparentemente estão dispostas longitudinalmente e não em posição helicoidal, diferente do que afirmaram outros autores ${ }^{20,21,22}$. Devido à forma da cabeça do espermatozóide ser ligeiramente helicoidal, a peça intermediária pode acompanhá-la, sendo que, mesmo havendo essa ligeira torção das mitocôndrias, ela não foi evidenciada nas observações do presente trabalho. A inserção da cauda por meio de dois centríolos foi descrita por Maretta ${ }^{23}$ e por nós observada, nessa documentação. Já Soley ${ }^{21,22}$, utilizando sêmen de avestruz para estudo, relata a presença do anel posterior do acrossoma, similar ao existente em sêmen de mamíferos, o que não foi possível observar nas 
eletromicrografias de sêmen de galo. No núcleo a cromatina é geralmente densa e levemente granular. Contudo, também foram observados espermatozói-des com cromatina com vários tipos de granulação e tonalidades de cinza, ou seja, com várias intensidades de compactação. Soley (1993 e 1996), relatou graus de compactação variados em uma mesma célula, devido à presença de pequenas regiões mais claras, indicativas de condensação incompleta do núcleo. Em nossas observações, geralmente as células com deficiência de compactação apresentavam todo o núcleo mais claro e, portanto, mal compactado. Nem sempre as alterações morfológicas observadas na microscopia eletrônica foram acompanhadas por má compactação da cromatina.

\section{Conclusões}

Sêmen de galos férteis possuem uma pequena quantidade de espermatozóides com baixa compactação de cromatina e alterações morfológicas.

Alterações na compactação da cromatina freqüentemente não são acompanhadas por alterações morfológicas, porém as alterações morfológicas geralmente são acompanhadas por alterações na compactação da cromatina.

\section{Morphology and chromatin condensation evaluation in fowl spermatozoa (Gallus gallus, Linnaeus, 1758) through the transmission electron microscopy}

\section{Abstract}

The spermiogram is one of the principal methods of evaluation of the fertility in mammals; however some semen modifications as the spermatozoa chromatin condensation, are not identified in this routine, and can expressively interfere in the fertility of reproducers. In poultry breeding, generally the evaluation of reproducers is made by sampling and the evaluated parameters are in fewer quantities than in mammals, considering the spermatozoa chromatin condensation of the fowl has never been exploited. The objective of this work is verifying through the transmission electron microscopy, whether there are different intensities of spermatozoa chromatin condensation of fowl. So that, have been collected 20 samples of fowl semen, which were placed in $4 \%$ glutaraldehyde buffered in $0.1 \mathrm{M}$ sodium cacodilate to $\mathrm{pH} 7.2$ for 48 hours, after being centrifugated and rinsed in cacodilate tampon, the semen was post-fixed in $1 \%$ osmium tetroxide plus $1.25 \%$ potassium ferrocyanide. The sediment was embedded, cut and contrasted. The thin sections were examined and documented in transmission electronic microscopy Zeiss EM-109. Generally the fowl spermatozoon has acrosome with homogenic or slightly granular and of moderate density material, the nucleus with dense or slightly granular chromatin, varies the gray scales, that is, the grades of condensation. It was also observed the "perforatorium", structure that links the nucleus to the acrosome. The insertion of the tail is made through two cetriules, being one transversal and the other longitudinal to the axle. The intermediate piece has typical axoneme involved by mitochondrias, apparently displayed longitudinally. The transition between the principal and the intermediate pieces of the tail is marked by the absence of the mitochondrias. The principal piece is formed by axoneme involved by a granular cytoplasm layer. In the evaluation of the morphological pathologies, it was observed rounded heads, folded, involved by the intermediate container of the
Key words:

Fowl.

Spermatozoon

Chromatin condensation. Fertility.

Ultrastructure. 
piece, in a hook and all of them showing different grades of condensation.

\section{Referências}

1 GILBERT, A. B. Ciclos reprodutivos: aves domésticas. In: HAFEZ, E. S. Z. Reprodução animal. São Paulo: Manole, 1982. p.488-515.

2 RUSSEL, L. D. et al. Evaluation of the testis. Clearwater: Cache River, 1990. 286 p.

3 BANKS, W. J. Histologia veterinária aplicada. São Paulo: Manole, 1992. 629 p.

4 HAFEZ, B.; HAFEZ, E. S. E. Reproduction in farm animals. Lippincoff: Williams \& Wilkins, 2000. 512 p.

5 AIRE, T. A. Ultrastructural study of spermiogenesis in the turkey, Meleagris gallopavo. Poultry Science, v. 44 , n. 5, p. 674-682, 2003.

6 LEWIN, L. M. et al. A comparative study of spermatozoal chromatin using acridine orange staining and flow cytometry. Comparative Biochemistry and Physiology Part A, v. 124, p. 133-137, 1999.

7 LOIR, M.; LINNEAU, M. Partial characterization of ram spermatid basic nuclear proteins. Biochemical and Biophysical Research Communications, v. 80, p. 974 982, 1978.

8 EVENSON, D. P.; DARZYNKIEWICZ, Z.; MELAMED, M. R. Relation of mammalian sperm chromatin heterogeneity to fertily. Science, v. 210, p. 1131-1133, 1980.

9 COURTENS, J. L.; LOIR, M. A citochemical study of nuclear changes in boar, bull, goat, mouse, rat and stallion spermatides. Journal of Ultrastructure Research, v. 74, p. 327-340, 1981.

10 BALHORN, R. A model for the struture of chormatin in mammalian sperm. Journal of Cell Biology, v. 93, p. 298-305, 1982.

11 CHIVA, M.; KASINSKY, H. F.; SUBIRANA, J. A. Characterization of protamines from four avian species. FEBS Letters, v. 215, n. 2, p. 237-240, 1987.

12 NAKANO, M. et al. Conformation of the fowl protamine, galline, and its binding properties to DNA. Journal of Biochemistry, v. 105, p. 133-137, 1989.

13 BELETTI, M. E. MELLO, M. L. S. Comparison between the toluidine blue stain and the Feulgen reaction of rabbit sperm chromatin condensation and their relationship with sperm morphology. Theriogenology, v. 62, n. 3,2004 .

14 NAKANO, M.; TOBITA, T.; ANDO, T. Studies on a protamine (galline) from fowl sperm. International Journal of Peptide and Protein Research, v. 7, p. 3146, 1975.

15 WILSON, J. L. Métodos para valorar la capacidad reproductiva en gallos reproductores. Avicultura Profesional, v. 6, n. 3, p. 76-81, 1988.

16 WATSON, M. L. Staining of tissue sections for electron microscopy with heavy metals. Journal of Biophysical and Biochemical Cytology, v. 4, p. 475478, 1958.

17 REYNOLDS, E. S. The use of lead citrate at high $\mathrm{pH}$ as an electron opaque stain in electron microscopy. Joural of Cell Biology, v. 18, p. 208-213, 1963.

18 BAKST, M. R.; BAHR, J. M. Ciclos reprodutivos: aves domésticas. In: HAFEZ, E. S. Z. Reproduçãoa Animal. 6 ed. São Paulo: Manole, 1995. p. 390-407.

19 BAKST, M. R.; SEXTON, T. J. Fertilizing capacity and ultrastructure of fowl and turkey spermatozoa before and after freezing. Journal of Reproduction and Fertility, v. 55, p. 1-7, 1979

20 THURSTON, R. J.; HESS, R. A. Ultrastructure of spermatozoa from domesticated birds: comparative study of turkey, chicken and guinea fowl. Scanning Microscopy, v. 1, n. 4, p. 1829-1838,1987.

21 SOLEY, J. T. Differentiation of the acrosomal complex in ostrich (Struthio camelus) spermatids. Journal of Morphology, v. 227, p. 101-111, 1996.

22 SOLEY, J. T. Ultrastructure of ostrich (Struthio camelus) spermatozoa: I. Transmission electron microscopy. Onderstepoort Journal of Veterinary Research, v. 60, n. 2, p. 119-130, 1993.

23 MARETTA, M. The behaviour of centrioles and the formation of the flagellum in rooster and drake spermatids. Cell and Tissue Research, v. 176, n. 265273, 1977. 